\title{
Língua Portuguesa no Timor-Leste: escrita e autoria ${ }^{1}$
}

\author{
Lengua portuguesa en Timor Leste: escritura y autoría
}

\section{Portuguese language in East Timor: writing and authorship}

\author{
Joice Eloi Guimarães²
}

\begin{abstract}
RESUMO: A língua portuguesa, a partir de 2002, passou a configurar como língua oficial e de instrução em Timor-Leste, juntamente com a língua tétum. Atualmente a língua portuguesa está sendo reintroduzida no país, com ações que recaem, sobretudo, em mudanças nos currículos escolares e na formação docente. A experiência com a formação de professores e futuros professores do ensino básico de Timor-Leste permitiu-nos observar que entre as dificuldades que esses sujeitos apresentam no que diz respeito à língua portuguesa a produção de textos ocupa lugar de destaque. Tendo em vista esse contexto, neste trabalho, analisamos as dificuldades com a produção e escrita da monografia em língua portuguesa de alunos concluintes do curso de Formação de Professores do Ensino Básico da Universidade Nacional de Timor Lorosa'e (UNTL). A análise dos enunciados de 27 alunos/as foi realizada tendo como referência a teoria do dialogismo de Mikhail Bakhtin, ressaltando, como categorias para análise, os conceitos de cronotopo e entonação (BAKHTIN, 2011). Com base na análise empreendida podemos afirmar que a grande maioria dos sujeitos integrantes desta pesquisa aponta a língua portuguesa como maior obstáculo para a escrita da monografia. Contudo, apesar dessa dificuldade, valora positivamente a obrigatoriedade da escrita desse gênero em português. Além disso, suas respostas conduzem à relação entre o domínio da linguagem e a capacidade de argumentação e sinalizam a dificuldade do sujeito sentir-se autor-criador, na acepção que confere Bakhtin a esse termo, de sua produção escrita em uma língua não materna.
\end{abstract}

PALAVRAS-CHAVE: Formação de professores. Escrita. Língua portuguesa. TimorLeste.

RESUMEN: Desde 2002, el portugués se ha convertido en un idioma oficial y ha sido utilizado en la educación en Timor Leste, junto con Tetum. Hoy en día, el portugués fue reintroducido en este país por medio de iniciativas que a menudo implican cambios en el currículo escolar y la formación docente. En nuestra experiencia en la educación de maestros y futuros maestros de educación básica, el mayor desafío que plantea el portugués es para aprender a escribirlo. Por esta razón, el objetivo del presente trabajo es analizar las dificultades que enfrentan los estudiantes de último año a

\footnotetext{
${ }^{1}$ Este artigo é uma versão ampliada da comunicação oral intitulada "Formação de professores em Timor-Leste o desafio da escrita em Língua Portuguesa" apresentado no XI Congresso Internacional da SIPLE - CONSIPLE, em 4 de novembro de 2016.
}

${ }^{2}$ Professora do Departamento de Estudos Brasileiros da Hankuk University of Foreign Studies, campus Global em Yongin, Coreia do Sul. Doutoranda em Linguística Aplicada (UNICAMP). 
escribir su tesis de pregrado para completar el programa de grado de Educación Primaria en la Universidad Nacional de Timor Leste (UNTL). Se analizaron las respuesdas dadas por los 27 estudiantes, utilizando la teoría del dialogismo de Mikhail Bakhtin como referencia. Los conceptos de cronotopo y la entonación se usaron particularmente como categorías de análisis. Nuestro análisis ha demostrado que la mayoría de los participantes en esta investigación consideran que el idioma portugués es el principal obstáculo para escribir su tesis de pregrado. Sin embargo, a pesar de esta dificultad, apreciar el requisito de escribir trabajos académicos en portugués. Además, las respuestas se refieren a la relación entre el dominio del lenguaje y la capacidad de argumentación y señalan que a los sujetos les resulta difícil sentirse autor-como-creador (en el sentido del término acuñado por Bakhtin) de su producción escrita en lengua materna.

PALABRAS CLAVE: Formación del profesorado. Escritura. Lengua portuguesa. Timor Leste.

ABSTRACT: Since 2002, Portuguese has become an official language and has been used in education in East Timor, together with Tetum. Nowadays, Portuguese has been reintroduced in this country by means of initiatives which most often involve changes in school curricula and teacher education. In our experience in the education of teachers and prospective basic education teachers, the greatest challenge posed by Portuguese is to learn how to write it. For this reason, the aim of the present work is to analyze the difficulties faced by senior students when writing their undergraduate thesis for completion of the Primary Education degree program at the National University of East Timor (UNTL). The utterances produced by 27 students were analyzed, using Mikhail Bakhtin's theory of dialogism as a reference. The concepts of chronotope and intonation were particularly used as categories of analysis. Our analysis has shown that most participants in this research consider the Portuguese language as the major obstacle to writing their undergraduate thesis. However, despite this difficulty, they appreciate the requirement of writing academic works in Portuguese. Moreover, their answers refer to the relationship between mastery of language and argumentative capacity and point to the fact that subjects find it difficult to feel like author-as-creator (in the sense of the term as coined by Bakhtin) of their written production in a non-native language.

KEYWORDS: Teacher education. Writing. Portuguese language. East Timor.

\section{Introdução}

Timor-Leste, ex-colônia portuguesa, após a restauração de sua independência, em 1999, elegeu como línguas oficiais e de instrução da então estabelecida República Democrática de Timor-Leste a Língua Portuguesa, 
doravante LP, e a língua Tétum ${ }^{3}$. Contudo, a LP nunca se configurou como língua utilizada cotidianamente pelos/as timorenses. Isso porque, durante os mais de 400 anos de colonização portuguesa, não houve, por parte da metrópole, investimentos efetivos em relação ao ensino e ao fomento de sua língua em solo timorense. Além disso, durante os 24 anos de invasão indonésia, de 1974 a 1999, foi proibido o uso da LP como recurso para estimular o projeto de dominação realizado pelo país vizinho ${ }^{4}$. A proibição do português durante o regime opressor da Indonésia proporcionou a LP o status de "língua de resistência" para o povo maubere, pois era utilizada como estratégia entre os/as integrantes da resistência timorense para se comunicarem e articularem suas ações. Porém, ainda hoje, é reduzido o número de timorenses proficientes em português.

Para a mudança desse quadro, desde eleita língua oficial e de instrução, o governo de Timor-Leste tem realizado ações para introduzir a LP nos contextos escolares - ações que demandam estratégias voltadas à formação inicial e continuada de docentes timorenses. Para tanto, conta com o auxílio de cooperações internacionais, como a cooperação brasileira. Por meio do Programa de Qualificação de Docentes e Ensino de Língua Portuguesa em Timor-Leste $(\mathrm{PQLP})^{5}$, foi-nos possível atuar em Timor durante dois anos em diversos níveis de ensino, inclusive na formação inicial e continuada de professores. Dentre as ações realizadas, destacamos no contexto desta pesquisa a realização de um curso de extensão intitulado "Pesquisa e produção textual: a escrita da monografia em Língua Portuguesa", por meio do qual recolhemos os dados que serão objeto de análise neste trabalho.

\footnotetext{
${ }^{3} \mathrm{~A}$ língua tétum configura-se como língua materna para uma significativa parte da população timorense, principalmente os residentes na capital, Díli. É a língua comumente utilizada pelos timorenses para as interações realizadas entre o povo timorense, possuidor de diferentes línguas maternas.

${ }^{4}$ Para mais informações sobre esse período e seus reflexos no âmbito educacional, cf. Carvalho (2007).

5 Programa de Qualificação de Docentes em Língua Portuguesa da Coordenação de Aperfeiçoamento de Pessoal de Nível Superior - CAPES, cujos principais três eixos de atuação são 1) formação inicial e continuada dos docentes, 2) fomento ao ensino da língua portuguesa e 3) apoio ao ensino superior.
} 
O público alvo deste evento formativo foram alunos da $7^{a}$ fase do curso de Formação de Professores do Ensino Básico da Universidade Nacional de Timor-Lorosa'e (UNTL). Durante o curso, por meio de instrumento de questionário, coletamos enunciados escritos produzidos pelos/as cursistas, tendo como tema a produção do gênero monografia em LP. Para análise desses enunciados, optamos pela abordagem sócio-histórica à luz da teoria do dialogismo desenvolvida por Mikhail Bakhtin e seu Círculo. Dessa linha teórica, utilizamos como categorias de análise elementos integrantes do contexto extraverbal dos enunciados - cronotopo (horizonte temporal e espacial - tempo (histórico) e espaço (social)) e entonação (caráter valorativo - elemento axiológico do enunciado; a avaliação social do sujeito que enuncia em relação ao objeto sobre qual ele enuncia).

Assim, por meio da discussão acerca dos temas língua não materna; ensino e formação docente e; produção escrita, visamos analisar dialogicamente os enunciados dos integrantes desta pesquisa tendo no horizonte de nosso olhar o contexto extraverbal de produção desses enunciados: os elementos sócio-históricos que dialogam com apropriação da LP pelos/as timorenses Timor-Leste.

Estruturalmente, este trabalho está organizado da seguinte forma: inicialmente, discutimos a temática da produção textual em contexto de ensino/aprendizagem de língua não materna. Em seguida, apresentamos uma breve contextualização acerca da formação inicial de docentes para o trabalho com a LP em Timor. Após, apresentamos a fundamentação teóricometodológica que norteia nosso olhar sobre os dados e descrevemos a etapa empírica da pesquisa: a realização do curso de extensão "Pesquisa e Produção textual: a escrita da monografia em Língua Portuguesa". Por fim, são realizadas as etapas de interpretação e análise dos dados e apresentadas algumas considerações da pesquisa.

\section{Produção de textos em língua não materna}


Ensinar uma língua não materna exige estratégias diferentes daquelas utilizadas no ensino de uma língua materna. Na crítica que realiza a orientação do pensamento filosófico-linguístico denominada de objetivismo abstrato, Bakhtin (2010, p. 104), apresenta algumas diferenças entre a língua materna e a língua não materna (denominada na obra de língua estrangeira). Enquanto "A palavra nativa é percebida como um irmão, como uma roupa familiar, ou melhor, como a atmosfera na qual habitualmente se vive e se respira. Ela não apresenta nenhum mistério.", no que diz respeito à língua não materna, para os autores, não há ainda o reconhecimento do signo, com suas possibilidades de sentido, apenas o reconhecimento do sinal, imutável e sempre idêntico a si mesmo. Conforme apontado em Guimarães (2015, p. 123), com base em Bakhtin (2010),

[...] o falante nativo de uma língua é capaz de compreender a palavra no seu contexto particular, com a ideologia que manifesta. A língua estrangeira, ao contrário, apresenta-se como um caminho misterioso. Nesse caso há apenas a identificação de um sinal, não a descodificação de um signo, pois esse é compreensível juntamente com o contexto de enunciação partilhado pelos sujeitos falantes de uma língua.

Tendo em vista que desde sua constituição como processo dialógico a linguagem é diferente nessas duas situações, cabe questionar como se realiza a produção de textos em uma situação em que os alunos não dominam a língua em que devem realizar suas produções escritas.

Nos últimos anos, no Brasil, sobretudo a partir da década de 1980, estudos e pesquisas têm sido desenvolvidos para que as práticas de ensino de linguagem realizadas na escola ocorram em uma perspectiva que considere a linguagem socialmente, como constitutiva e constituinte dos sujeitos. Bakhtin e integrantes do seu Círculo são autores frequentemente utilizados para se pensar nesse sentido, pois, na acepção desses estudiosos, a linguagem é dialógica, ocorre sempre na relação com o outro. Nessa perspectiva, em relação à didática de línguas, o caminho metodológico tem início "na interação verbal - 
desencadeada no momento das enunciações - ligada à situação concreta e ampla em que ocorre, para então entendê-la em meio à corrente verbal, expressa na materialidade linguística dos textos." (GUIMARÃES, 2013, p. 59).

Defendemos que tal entendimento é válido, também, para quando pensamos na didática de língua não materna, ou seja, contextos em que a língua que se procura ensinar configura-se como língua segunda, língua estrangeira, etc. para o sujeito aprendente. Como o próprio autor afirma,

O ponto de vista que defendemos, embora careça de uma sustentação teórica, constitui, na prática, a base de todos os métodos eficazes de ensino de línguas vivas estrangeiras. $O$ essencial desses métodos é familiarizar o aprendiz com cada forma da língua inserida num contexto e numa situação concretas. Assim, uma palavra nova só é introduzida mediante uma série de contextos em que ela figure. [...] Em suma, um método eficaz e correto de ensino prático exige que a forma seja assimilada não no sistema abstrato da língua, isto é, como uma forma sempre idêntica a si mesma, mas na estrutura concreta da enunciação, como um signo flexível e variável. (BAKHTIN, 2010, p. 98).

$\mathrm{Na}$ situação aqui analisada, situação formal de ensino no contexto acadêmico de Timor-Leste, o desafio é que o aluno sinta-se produtor de seu texto, colocando-se na posição de enunciador, capaz de produzir significados a partir da língua escrita, atendendo, em menor ou maior grau, as suas necessidades comunicativas na modalidade escrita.

\section{A produção de textos em Língua Portuguesa na formação inicial de professores/as de Timor-Leste}

As diretrizes curriculares atuais de Timor-Leste apontam para a importância $\mathrm{da}(\mathrm{s})$ língua(s) que $\mathrm{o}$ aluno domina no processo de aquisição/desenvolvimento de uma língua segunda, como a LP no contexto timorense. Sendo assim, tais línguas participam desse processo, em um plano de progressão linguística, que tem início no pré-escolar aumentando gradativamente sua carga horária até o ensino secundário. De acordo com o Decreto-Lei 4/2015, Artigo 140: 


\begin{abstract}
É garantida uma progressão gradual do Tetum ao Português, de modo a que esta última constitua a principal língua objeto da literacia e de instrução no terceiro ciclo do ensino básico, e que, no final do ensino básico, os alunos tenham adquirido um nível semelhante de conhecimento de ambas as línguas oficiais (TIMORLESTE, 2015).
\end{abstract}

Dessa forma, os/as professores envolvidos nos diferentes níveis de ensino em Timor-Leste dialogam, em menor ou maior grau, com a LP. Porém, no ensino superior, especificadamente no curso de Formação de Professores do Ensino Básico da UNTL, de acordo com nossa experiência, podemos afirmar que, os/as professores/as e futuros/as professores/as leste-timorenses apresentam, ainda, muitas dificuldades em relação ao uso e à compreensão da LP.

No que diz respeito, especificadamente, à produção escrita em português, as fragilidades em termos de domínio desta competência linguística e comunicativa acentuam-se e tornam-se particularmente visíveis. Isso pelo fato de existir a obrigatoriedade de os estudantes universitários escreverem uma monografia em LP como requisito para a conclusão dos cursos de Licenciatura na Faculdade de Direito e nos Departamentos de Formação de Professores do Ensino Básico e de Língua Portuguesa da Faculdade de Educação, Artes e Humanidades (FEAH).

Diante dessa verificada dificuldade, passamos agora a análise da grade curricular do curso de Licenciatura em Formação de Professores do Ensino Básico da Faculdade de Educação, Artes e Humanidades (FEAH) ${ }^{6}$, na tentativa de averiguar em que medida esse currículo auxilia os/as futuros/as docentes com subsídios teórico-metodológicos para a produção escrita em LP.

A grade curricular prevista para os 4 anos de curso, divididos em 8 semestres letivos, apresenta, nas 5 primeiras fases, 5 componentes curriculares de Língua Portuguesa. Em relação aos gêneros escritos constantes nessas

\footnotetext{
${ }^{6}$ Este curso destina-se a formar professores/as para o trabalho no $1^{\circ}, 2^{\circ}$ e $3^{\circ}$ ciclos do ensino básico de Timor-Leste.
} 
disciplinas, temos: nas disciplinas Língua Portuguesa I e Língua Portuguesa II, os gêneros escritos que constam são praticamente os mesmos - relato de atividades, carta, carta formal, bilhete e currículo profissional. Na disciplina Língua Portuguesa II há menção ao gênero guia turístico. A disciplina Língua Portuguesa III destina-se ao estudo da classe gramatical dos verbos, enquanto a Língua Portuguesa IV foca na sintaxe da língua portuguesa e a Língua Portuguesa $V$ na semântica da língua.

O que podemos constatar de antemão, é que as disciplinas intituladas "Língua Portuguesa" quando elegem para o trabalho didático gêneros, a escolha recai sobre gêneros primários que se encontram, sobretudo, em situações de uso comuns aos/às alunos/as. Em relação aos aspectos metodológicos, contudo, essa característica social não é explorada, pois esses estão voltados às questões relacionadas à estrutura e funcionamento da língua. Além disso, observamos que, nessas disciplinas, não há uma preparação do/da estudante ao desenvolvimento de gêneros acadêmicos escritos, como a monografia.

O trabalho com gêneros específicos da esfera acadêmica aparece no currículo no terceiro ano do curso, na $5^{a}$ fase, com a disciplina "Desenvolvimento da Escrita Científica". Conforme sua ementa, os conteúdos previstos englobam a história da escrita; o estudo de gêneros acadêmicos - 0 projeto de pesquisa e a monografia -, os tipos de pesquisa e os métodos científicos. Não há, nesse documento, menção ao fato de esse gênero ser escrito em uma língua que não é a língua materna dos alunos.

Na 6a fase, os conteúdos previstos na disciplina "Metodologia para o ensino da Língua Portuguesa" dizem respeito aos processos de ensino e aprendizagem de LP nas diferentes práticas de linguagem. No último ano do curso, há a disciplina "Metodologia Científica e Seminário". Entre as avaliações apontadas nessa disciplina está a escrita de um projeto investigativo. Na $6^{a}$ 
fase há ainda a disciplina intitulada "Monografia" que é destinada à produção das etapas da pesquisa monográfica?

Sabemos que os conteúdos previstos em um currículo prescrito nem sempre são possíveis de serem trabalhados na prática. No caso de Timor-leste essa afirmação é confirmada devido a vários fatores, sendo o principal deles a dificuldade teórico metodológica que os próprios docentes universitários têm com o gênero monografia e com a escrita em LP8.

\title{
Fundamentação teórico-metodológica
}

A fundamentação teórico-metodológica que orienta esta pesquisa tem como base os estudos desenvolvidos por Bakhtin e integrantes do grupo de estudiosos, posteriormente conhecido como Círculo de Bakhtin. Na perspectiva desses autores, linguagem e vida não podem ser dissociados, pois, os sujeitos se constituem nas e pelas interações de que participam, ou seja, a relação eux outro é condição de existência. Nas palavras de Bakhtin (2011, p. 348):

\begin{abstract}
A vida é dialógica por natureza. Viver significa participar do diálogo: interrogar ouvir, responder, concordar, etc. Nesse diálogo o homem participa inteiro e com toda a vida: com os olhos, os lábios, as mãos, a alma, o espírito, todo o corpo, os atos. Aplica-se totalmente na palavra, e essa palavra entra no tecido dialógico da vida humana, no simpósio universal.
\end{abstract}

A materialização dessas relações dialógicas ocorre por meio de enunciados, que são "as unidades concretas da comunicação discursiva e se constituem dialogicamente no contexto histórico, social e ideológico de uma época." (GUIMARÃES, 2015, p. 134). Os enunciados fazem parte da cadeia de comunicação discursiva e a ela estão ligados, respondendo a outros enunciados, ou antecipando-se em relação a eles. Cada enunciado é único e

\footnotetext{
${ }^{7}$ De acordo com a grade curricular do curso de Formação de Professores do Ensino Básico da UNTL, a carga horária dessa disciplina comporta 14 horas de estudo autónomo do estudante sobre o projeto de monografia e 7 horas de aulas teórica e prática.

8 Essa afirmação se baseia na experiência docente em Timor-Leste e na experiência de coorientação de monografia no Departamento de Formação de Professores da UNTL.
} 
irrepetível e, para alcançarmos seu sentido, seu tema, precisamos ir além dos aspectos estritamente linguísticos e conhecer o contexto extraverbal, a situação social em que ele é produzido.

Dos elementos constantes nesse contexto extraverbal, utilizamos como categorias de análise nesta pesquisa os conceitos de cronotopo (tempo e espaço) e de entonação (caráter valorativo) na produção dos enunciados.

O conceito de cronotopo envolve as relações temporais e espaciais na produção dos enunciados, ou seja, onde e quando o enunciado é produzido são elementos que estão "fora", mas participam de sua composição. Apesar de ter sido desenvolvido inicialmente visando à esfera literária, esse conceito é importante para o estudo de outros gêneros, já que "qualquer intervenção na esfera dos significados só se realiza através da porta dos cronotopos" (BAKHTIN, 2002, p. 362). Nesse mesmo viés, aponta Amorim (2010) que a partir do cronotopo é possível projetar uma visão de homem, uma vez que, sendo o cronotopo uma produção da história, "Designa um lugar coletivo, espécie de matriz espaço-temporal de onde as várias histórias se contam ou se escrevem." (AMORIM, 2010, p. 105). Do mesmo modo, ainda segundo a autora, permite uma visão de um modelo de sociedade que, por sua vez, influencia também na construção dos enunciados.

A inter-relação do cronotopo com a produção dos enunciados não se dá de maneira evidente ou em uma relação direta. Fazem parte desse processo as vozes sociais presentes nos diferentes cronotopos em que os enunciados são proferidos. Para Guimarães (2013, p. 38), "Essas vozes configuram-se como representantes das ideologias de grupos sociais específicos em determinados tempos e espaços históricos e atuam, portanto, de modos distintos no processo de construção dos enunciados".

$\mathrm{Na}$ acepção de Bakhtin (2010, p. 32), "Todo signo está sujeito aos critérios de avaliação ideológica (isto é, se é verdadeiro, falso, correto, justificado, bom, etc.)". Os sujeitos, nas relações dialógicas, assumem uma posição ativamente responsiva, em que entram em jogo uma infinidade de 
posicionamentos valorativos sobre o objeto que enunciam. Sendo assim, essa valoração reflete determinadas construções ideológicas que pairam na sociedade e que ali permanecem como "valorações subentendidas" e são elementos constitutivos do enunciado (BAKHTIN, 2010).

À luz dessa perspectiva, o enunciado não pode, nunca, ser neutro, pois sua produção ocorre em determinado cronotopo atravessado por índices sociais de valor, cuja escolha representa a posição ativa do sujeito que enuncia perante seu objeto e interlocutor. Esses conceitos imbricam-se, pois, ao enunciar, em qualquer situação, o sujeito o faz em determinado cronotopo e dialoga (responde ativamente) a outros enunciados, movimento que ocorre a partir de sua posição axiológica. Essa tomada de posição diante de outros enunciados, ou seja, diante de vozes sociais presentes nesses enunciados, configura uma posição de autoria, no sentido atribuído por Bakhtin (2011) ao termo.

Ao longo dos estudos realizados por Bakhtin, fazem-se presente as temáticas concernentes ao autor e à autoria, tanto na análise de obras de caráter literário como de enunciados construídos nas interações sociais das quais os sujeitos fazem parte (FARACO, 2008). Nas palavras de Bakhtin (2011, p. 389):

\footnotetext{
A forma de autoria dependo do gênero do enunciado. Por sua vez, o gênero é determinado pelo objeto, pelo fim e pela situação do enunciado. [...] Quem fala e a quem se fala. Tudo isso determina o gênero, o tom e o estilo do enunciado: a palavra do líder, a palavra do juiz, a palavra do mestre, a palavra do pai, etc. É isso que determina a forma da autoria.
}

Bakhtin estabelece uma distinção entre o autor-pessoa e o autor-criador. A distinção entre esses dois conceitos se dá na observância da relação que os mesmos estabelecem com o objeto e com as valorações que este carrega.

No caso dos enunciados, podemos, analogamente, pensar nessa distinção da seguinte forma: ao tratar de um tema, no caso a escrita da 
monografia em LP, o autor-pessoa vai selecionar, na cadeia da comunicação discursiva, seu recorte valorativo. No momento em que vai além desse movimento, ultrapassando seu próprio recorte valorativo da realidade, ocorre a (re) significação do recorte realizado pelo autor-pessoa, ele, então, passa a criar. Temos, nesse momento, o nascimento do autor-criador, que assume uma posição exotópica e axiológica, dando acabamento à obra de forma dialógica, guiando o leitor na sua maneira de ver o mundo. Segundo Faraco (2008, p. 40), "Mesmo que a voz do autor-criador seja a voz do escritor como pessoa, ela só será esteticamente criativa se houver deslocamento, isto é, se o escritor for capaz de trabalhar em sua linguagem permanecendo fora dela." Quando esse movimento de (re) significação não acontece, e então a voz do autor-pessoa permanece como tal, essa linguagem "é para Bakhtin, ingênua e inadequada para a autêntica criação estética." (FARACO, 2008, p. 40).

Trazemos para o escopo deste trabalho esse conceito de Bakhtin, tendo em vista o sujeito timorense e sua possibilidade de dialogar com os "outros" entenda-se outros enunciados que provêm da voz social e dela foram recortados para, a seguir, serem inseridos em outro plano, o texto desses sujeitos.

\section{A realização do curso de extensão "Pesquisa e Produção textual: a escrita da monografia em Língua Portuguesa" - Caminhos metodológicos}

Diante da já mencionada dificuldade dos/das estudantes timorenses em produzir uma monografia em LP, durante nossa experiência com a formação de professores/as e futuros/as professores/as do ensino básico de Timor na Universidade Nacional de Timor Lorosa'e (UNTL) propusemos a realização de um curso de extensão cuja temática abordava o gênero monografia e a escrita científica em LP. O curso, denominado "Pesquisa e produção textual: a escrita 
da monografia em Língua Portuguesa", teve duração de 30h, divididas em 10 encontros ocorridos no período de férias letivas, em janeiro de 2016.

$O$ referido curso foi estruturado em torno dos seguintes objetivos: (i) Desenvolver discussões relacionadas às etapas de construção de uma pesquisa científica; (ii) Proporcionar um aparato teórico e prático em relação à escrita do gênero monografia, bem como desenvolver a compacidade textual e discursiva; (iii) Desenvolver habilidade de argumentação e defesa crítica de ideias; (iv) Construir textos coesos e coerentes com o uso de citações, paráfrases e elementos intertextuais e; (v) Proporcionar a autocorreção e a correção coletiva de aspectos da Língua Portuguesa.

Ao todo, 27 professores/as e futuros/as professores/as timorenses, alunos/as da $7^{a}$ fase do curso de Licenciatura em Formação de Professores do Ensino Básico da UNTL participaram do curso. No último dia de encontro, aplicamos um questionário composto de 5 questões que objetivavam conhecer as dificuldades desses sujeitos em relação à produção escrita em LP e ao gênero monografia.

Os enunciados escritos produzidos pelos/as cursistas como respostas a essas questões constituem o banco de dados coletados para esta pesquisa. Destacamos para analisar, dentre as respostas produzidas, aquelas referentes a duas questões: na primeira o/a cursista deveria assinalar, entre duas opções, aquela que representava sua maior dificuldade para produzir a monografia: (i) As etapas da pesquisa e/ou (ii) A escrita em Língua Portuguesa. Em seguida, foi solicitado que eles/as justificassem sua escolha; na segunda questão, cujas respostas trouxemos para análise, foi solicitado que o/a cursista respondesse a seguinte pergunta: Se a escrita da monografia pudesse ser em outra língua de sua escolha, que língua você escolheria?

Sendo assim, nosso corpus de análise é composto por 27 enunciados escritos recolhidos ao final da realização do curso de extensão "Pesquisa e Produção textual: a escrita da monografia em Língua Portuguesa". A partir dos quais realizaremos a análise, utilizando-nos dos conceitos de cronotopo e 
entonação, a fim de verificar se esses sujeitos sentem-se na posição de autorcriador, na acepção que confere Bakhtin a esse termo, de sua produção escrita em uma língua não materna.

\section{Análise das produções: cronotopo e entonação e a possibilidade de autoria em produções escritas de timorenses em língua portuguesa}

A construção dos enunciados dos docentes que integram esta pesquisa precisa ser compreendida considerando que, em certa medida, esses sujeitos vivenciam a obrigatoriedade de uso da LP, ou seja, seus discursos são construídos tendo no horizonte de sua produção uma palavra de autoridade. Esse cronotopo específico influencia, certamente, na produção dos enunciados, pois ao mesmo tempo em que molda a produção dos enunciados o cronotopo é construído por meio dos enunciados que são produzidos em seu interior.

No caso desta pesquisa a produção dos enunciados analisados se deu em um tempo-espaço determinado: a última aula do curso de extensão "Pesquisa e produção textual: a escrita da monografia em Língua Portuguesa". Esse cronotopo, por sua vez, insere-se em outro cronotopo maior - aquele em que ocorre a reintrodução da LP nas práticas educativas em Timor, com a presença de políticas e de incentivos para a formação inicial e continuada de docentes nesse sentido.

Tendo em conta essa realidade contextualizada, e as valorações que são construídas nela, apresentamos o quantitativo de respostas à primeira questão aplicada, a qual solicitava que os/as cursistas apontassem a maior dificuldade em produzir a monografia: 4 cursistas apontaram como maior dificuldade as etapas de realização da pesquisa científica; 15 a escrita em Língua Portuguesa e; 8 cursistas assinalaram ambas as opções anteriores. Conforme podemos observar por meio dessas respostas, a maioria dos/as participantes aponta como maior dificuldade no processo de produção da monografia a escrita em 
LP. Abaixo apresentamos algumas justificativas ${ }^{9}$ utilizadas por aqueles/as que escolheram essa opção:

Exemplo1: $A$ escrita em lingua portuguesa e mais difícil porque a lingua tem pontuação. tem virgula. e tambem atraves de palavras que mais dificil para $\min$.

Exemplo 2: A escrita em lingua Portuguesa é dificil, por causa da lingua que aprendi é pouco, mas para produzir a monografia em Lingua Portuguesa com o texto muito comprido e preciso conjugar os verbos com os três tempos presente, futuro e passado.

Exemplo 3: Porque a lingua portuguesa e mais dificil para me principal na conjugação do verbo em tempo presente, passado e futuro e também outras palavras que eu não sei com lingua portuguesa.

Em relação a maior dificuldade apresentada pelos/as cursistas, a escrita em LP, observamos que grande parte das justificativas está relacionada à estrutura da língua, às normas gramaticais. Vemos também, nos exemplos 1, 2 e 3, que a dificuldade com a LP é justificada por um entendimento, consenso entre os/as timorenses, de que essa língua é muito difícil. Esse enunciado comum se constrói, sobretudo, na relação de comparação com a língua tétum, língua de forte tradição oral, que só conheceu uma norma ortográfica oficial em $2004^{10}$. Além disso, a utilização dos verbos na língua tétum ocorre de forma mais simples se comparada ao português, não há, por exemplo, conjugação de

\footnotetext{
${ }^{9}$ Os trechos foram transcritos conforme original.

10 A "Gramática da Língua Tétum" foi escrita pelo linguista australiano Geoffrey Hull e seu parceiro Lance Eccles. Nela, os autores seguem os preceitos do Instituto Nacional de Linguística (INL) da Universidade Nacional de Timor Lorosa'e, os quais apontam o tétum praça como a base literária da língua nacional e, dessa forma, excluem as palavras importadas da língua indonésia, dando preferência aos termos do tétum praça de origem indígena e portuguesa.
} 
número e pessoa e a conjugação de tempo se dá com o auxílio de advérbios que fazem a marcação temporal.

Podemos inferir que os enunciados dos participantes desta pesquisa não estão centrados no aspecto discursivo da língua, e sim no aspecto estrutural, o que remete a uma concepção de linguagem de viés estruturalista, num entendimento de que, para utilizar uma língua é preciso conhecer a sua estrutura.

Abaixo, apresentamos um exemplo que vai além e coloca a dificuldade na incapacidade de estabelecer um diálogo com o autor do texto em LP.

Exemplo 4: O principal dificuldade que enfrentei para produzir a monografia por causa da lingua portuguesa, que eu tenho dificuldade de analisar a ideia do autor.

Vemos aqui um movimento em direção ao plano discursivo da linguagem, ou seja, que aponta um impedimento em estabelecer relações dialógicas com o enunciado do autor, impedimento que é resultado da dificuldade, para o falante não nativo de uma língua, em alcançar as infinitas possibilidades de sentido do signo enquanto material ideológico. $O$ que ocorre, nesse caso, é a tentativa, por parte do/a aluno/a, de acessar e abrir caminho "no mundo misterioso de uma língua estrangeira." (BAKHTIN, 2010, p. 102).

Após a escrita em LP, o segundo maior número de cursistas (8) colocou as duas opções como dificuldades. Abaixo apresentamos alguns exemplos de suas justificativas para tal escolha:

Exemplo 1: Por que para me, monografia é primeira vez então eu sinto que muita dificuldade. Em lingua portuguesa dificuldade na conjugações da gramatica. 
Exemplo 2: Porque eu sinto é uma dificuldade para organizar e escrever a monografia porque é primeira vez e tambem a dificuldade para expressar em lingua portuguesa e tambem para as realizações da pesquisa.

Exemplo 3: A principal dificuldade para produzir a monografia são estes duas questões: sobretudo as etapas de realização da pesquisa que muitas vezes enfrentei como escrever a monografia e de onde começo e como termina e também a relação a escrita em língua portuguesa.

Nos exemplos colocados acima, há novamente a referência ao aspecto estrutural da LP e também, em relação à produção da monografia, é citado o desconhecimento desse processo, por ser a primeira vez que o realizam. Esse argumento nos remete à crítica em relação à formação desses sujeitos no que diz respeito à preparação para a escrita de gêneros científicos em LP. Como vimos, há apenas uma disciplina destinada a esse ponto e nela são priorizados aspectos concernentes à história e ao desenvolvimento da escrita e não os aspectos práticos da efetiva produção escrita. Além disso, a especificidade da escrita do gênero monografia em uma língua que não é a língua materna dos timorenses não é mencionada.

Apenas 4 cursistas manifestaram terem dificuldades apenas com as etapas da monografia, opção que deixa entrever que, para esses sujeitos a LP não se configura como a maior dificuldade no processo de escrita da monografia em português.

Contudo, no exemplo 1, no qual o/a cursista remete a um bom orientador a ajuda para realizar a monografia, vemos que a esse orientador cabe, na acepção desse sujeito, a função de "dar correção".

Exemplo1: Na etapa de realização da pesquisa precisa de ter um bom orientador para me dar coreção. 
No exemplo 2, fica evidente a dúvida em relação à pesquisa de caráter científico atrelada à realidade plurilíngue observada em Timor-Leste:

Exemplo 2: A minha dificuldade é "como é que eu vou pesquisar?" porque na minha escola muitas crianças sempre utilizar varias línguas.

Muitos/as timorenses defendem que a LP deve ser a única língua utilizada no espaço escolar, excluindo dessa forma as demais línguas nativas presentes em Timor. Tal posicionamento vai de encontro às orientações que preconizam o ensino das línguas maternas e da língua tétum ao lado do português ${ }^{11}$.

Apesar das dificuldades apontadas pelos/as integrantes desta pesquisa, as quais recaem, principalmente sobre a escrita em LP, observamos, por meio das respostas à questão "Se a escrita da monografia pudesse ser em outra língua de sua escolha, que língua você escolheria?" expostas na Tabela 1, que a maioria desses sujeitos opta pela LP.

Tabela 1 - quantitativo das respostas dos cursistas em relação a língua de escolha para a escrita da monografia.

\begin{tabular}{|l|l|}
\hline Língua Portuguesa & 20 \\
\hline Tétum & 01 \\
\hline Língua Portuguesa e Bahasa Indonésia & 02 \\
\hline Língua Portuguesa e Tétum & 01 \\
\hline Tétum ou Bahasa Indonésia & 01 \\
\hline Não respondeu & 02 \\
\hline Total & 27 \\
\hline
\end{tabular}

Fonte: Autor(es).

\footnotetext{
${ }^{11}$ Exemplo recente disso é a notícia de que em uma escola básica localizada no município de Dili foi aplicada uma regra que proíbe os seus estudantes em falar a língua local ou a língua materna dentro daquele estabelecimento de ensino, sendo o Português a única língua autorizada. Os/as alunos/as que utilizem nesse espaço de ensino outra língua, que não o português, serão multados. "A diretora da escola sublinha que esta regra foi estabelecida com o consentimento dos pais e encarregados de educação dos alunos. A professora justifica que aplicou a multa de forma a ajudar os alunos a falarem Português." (TIMOR-LESTE..., 2016).
} 
Em relação à opção pela escrita em $L P$, informação que se contrapõe aquela apresentada anteriormente, cuja principal dificuldade seria a escrita nessa língua, temos algumas justificativas que podem ser separadas em dois grupos: (i) ajudaria a aprimorar o conhecimento da língua e, (ii) a oficialidade do português.

Exemplo 1: As vantagens de escrever a monografia utilizar a lingua portuguesa desenvolve o meu conhecimento sobre a lingua portuguesa.

Exemplo 2: Para mim sempre escolhei a língua portuguesa para produzir a monografia, porque tem regras. Posso produzir um livro para guardar na biblioteca e posso conhecer sobra a língua mais profunda.

Exemplo 3: Para aumentar conhecimento da lingua portuguesa.

Os exemplos apresentados acima reforçam a ideia de obrigatoriedade de esses sujeitos saberem a LP. Tal ideia, internalizada por eles, é colocada em primeiro plano sendo, neste caso, a pesquisa científica um caminho para atingila. Observamos que a produção da monografia, nesses enunciados, é dissociada de sua importância que é referente a ela mesma, como processo de construção de conhecimento, busca de solução para um problema, etc.

Nos exemplos 4 e 5 apresentados a seguir, vemos a forte presença de uma palavra de autoridade.

Exemplo 4: A vantagem é baseando no curso durante quatro anos aprender essa lingua, porque essa língua oficial precisa de saber melhor.

Exemplo 5: As vantagens, posso saber mais a língua portuguesa por meio da prática e da escrita. Porque este língua é a nossa lingua oficial que já tinha aprovada na constituição da RDTL no artigo 13. 
Segundo Bakhtin (2011), em cada época e em cada esfera de organização social coexistem enunciados que gozam de prestígio, que são seguidos pelos grupos sociais pertencentes a essas esferas. Nesse contexto a palavra de autoridade, como a representada pela lei (decretos, constituições, etc.) preexiste para os sujeitos de determinado grupo social, pois, as esferas de que provêm essas vozes atribuem, aos enunciados que produzem, o caráter de verdade, ou seja, sua palavra representa uma palavra de autoridade na sociedade.

Como podemos observar nos enunciados produzidos pelos/as cursistas e também naquilo que eles expressam, a uma grande dificuldade em dialogar com a LP em suas produções. A nosso ver, os/as timorenses no processo de escrita em LP fazem o movimento de buscar certas posições e valorações com as quais concordam e inserir em seus enunciados, perfazendo assim o autorpessoa denominado por Bakhtin. Não estamos afirmando a impossibilidade de existir o autor-criador nesses contextos de produção em uma língua não materna. Porém, nossa análise mostra que para esses sujeitos é, ainda, muito difícil, realizar o deslocamento necessário à configuração da autoria. Como aponta Faraco (2008, p. 43) com base em Bakhtin, "sem deslocamento não há ato criador".

\footnotetext{
Para isso (para posicionar-se axiologicamente frente à própria vida), o escritor precisa dar a ela um certo acabamento, o que ele só alcançara se distanciar-se dela, se olhá-la de fora, se tornar-se um outro em relação a si mesmo. Em outros termos, ele precisa se autoobjetivar, isto é, precisa olhar-se com um certo excedente de visão e conhecimento (FARACO, 2008, p. 43).
}

Com base na análise das respostas obtidas nesta pesquisa, podemos inferir que, o nível de conhecimento de LP que esses sujeitos apresentam é, certamente, um entrave para que os mesmos possam realizar esse segundo movimento. Em nossa opinião, para que o sujeito constitua-se como autorcriador de seus textos em língua não materna é necessário um conhecimento 
da língua que vai além de aspectos estruturais, que estão no plano discursivo, para que ele/a seja capaz de estabelecer relações dialógicas com os demais enunciados que integram a cadeia de comunicação discursiva da língua em que deseja se expressar. Dessa forma, tendo em vista os aspectos composicionais concernentes ao gênero monografia, há, ainda, um longo caminho a ser percorrido para que os/as sujeitos timorenses atuem como autores-criadores de suas produções em LP.

\section{Algumas considerações}

A produção dos enunciados dos/as cursistas que participaram desta pesquisa reflete e refrata o contexto de sua produção: o processo de reintrodução da LP nos currículos escolares de Timor-Leste e a necessidade de formação docente nesse sentido.

Vimos que há um embate entre diferentes posições valorativas as quais são trazidas por esses sujeitos para as respostas, sobretudo, aquelas com sentidos instituídos em relação à LP em Timor: a dificuldade de compreensão de sua estrutura linguística, principalmente tendo como parâmetro a estrutura da língua tétum. Também a ideia de que a monografia seria um instrumento de aprendizagem da LP, ideia que não contrariamos, contudo não podemos ignorar as outras aprendizagens que essa produção objetiva.

No caso específico da produção da monografia em LP no curso de Formação de Professores do Ensino Básico da UNTL, sugerimos que haja, desde o início, nas disciplinas que compõem a grade curricular desse curso, uma preocupação com a prática de produção de textos, como atividade regular e progressiva de gêneros primários e secundários. É preciso atentar também para as metodologias utilizadas, que devem ser voltadas para a produção de textos em uma língua não materna. Tais medidas, acreditamos, podem diminuir as dificuldades que os timorenses têm com a escrita em LP, possibilitando a esses 
sujeitos colocarem-se na posição de autores-criadores de seus textos nessa língua.

Sabemos que o caminho a ser percorrido é longo e cheio de obstáculos, contudo é preciso que se estabeleçam mudanças para que os/as estudantes timorenses possam aproveitar da pesquisa para aprofundar questões importantes em relação à educação em Timor-Leste. Isto só será possível se eles forem capazes de dialogar, posicionar-se em LP, construindo, dessa forma, novos conhecimentos. 


\section{Referências}

AMORIM, Marília. Cronotopo e exotopia. In: BRAIT, Beth (Org.). Bakhtin: outros conceitos chave. São Paulo: Contexto, 2008. p. 95-114.

BAKHTIN, Mikhail Mikhailovich. Estética da criação verbal. 6. ed. São Paulo: Martins Fontes, 2011.

BAKHTIN, Mikhail Mikhailovich. Formas de tempo e de cronotopo no romance: ensaios de poética histórica. In: - Questões de literatura e de estética: a teoria do romance. Tradução: Aurora Fornoni Bernadini et al. 5. ed. São Paulo: Hucitec, 2002. p. 211-362.

BAKHTIN, Mikhail Mikhailovich. Marxismo e filosofia da linguagem. 14. ed. São Paulo: Hucitec, 2010.

CARVALHO, Manuel Belo de. Formação de professores em Timor-Leste: contributos para a construção de um modelo de formação inicial e contínua. 2007. Dissertação (Mestrado em Educação) - Universidade do Minho, Braga, 2007.

FARACO, Carlos Alberto. Autor e autoria. In: BRAIT, Beth (Org.). Bakhtin: conceitos-chave. São Paulo: Contexto, 2008. p. 37-60.

GUIMARÃES, Joice Eloi. O programa Olimpíada de Língua Portuguesa: escrevendo o futuro e sua relação com as ações pedagógicas na sala de aula. 2013. 206 f. Dissertação (Mestrado em Educação) - Universidade Federal de Santa Catarina, Florianópolis, 2013.

GUIMARÃES, Joice Eloi. Olhar dialógico para o ensino de língua portuguesa em Timor-Leste. Revista Advérbio, Cascavel, v. 10, n. 20, p. 120-135, 2015.

TIMOR-LESTE. Decreto-Lei n04/2015, de 14 de Janeiro. Aprova o currículo nacional de base da educação pré-escolar. Jornal da República, Dili, série $1, \mathrm{n}$. 2, p. 7736, 14 jan. 2015. Disponível em: <http://www.mj.gov.tl/jornal/public/docs/2015/serie_1/SERIE_I_NO_2.pdf>. Acesso em: 30 jan. 2015.

TIMOR-LESTE: "Quem não souber falar Português é melhor estar calado", diz uma diretora de uma Escola Básica. Global Voices, 18 jul. 2016. Disponível em: <https://pt.globalvoices.org/2016/07/18/timor-leste-quem-nao-souber-falarportugues-e-melhor-estar-calado-diz-diretora-de-uma-escola-basica/> . Acesso em: 28 set. 2016. 